\title{
28 Research Square \\ Identification and Deletion of The Genes Responsible for Hydrogen Production in Thermoanaerobacter \\ Ethanolicus JW200
}

Xiongjun Shao ( $\square$ xiongjun_shao@hotmail.com )

Hubei University https://orcid.org/0000-0002-0358-4553

Christopher D. Herring

Dartmouth College

Yuanxin Zhang

Hubei University

Gang Zhang

Hubei University

Liang Tian

Dartmouth College

Lee R. Lynd

Dartmouth College

\section{Research}

Keywords: Thermophilic bacteria, hydrogen production, hydrogenase enzymes, biofuel, anaerobic metabolism, fermentation, gene deletion

Posted Date: November 1st, 2021

DOI: https://doi.org/10.21203/rs.3.rs-993030/v1

License: (a) (i) This work is licensed under a Creative Commons Attribution 4.0 International License. Read Full License 


\section{Abstract \\ Background}

Thermoanaerobacter ethanolicus produces a considerable amount of ethanol from a range of carbohydrates and is an attractive candidate for applications in bioconversion processes. Due to the coupling of hydrogenase activity with fermentation product distribution, understanding hydrogen production of $T$. ethanolicus, particularly the genes responsible, is valuable for metabolic engineering of the species.

\section{Results}

Utilizing the hydrogenases reported in Thermoanaerobacterium saccharolyticum and Pyrococcus furiosus as templates, BLAST search identified five hydrogenase gene clusters, including two membrane-bound [NiFe] hydrogenases ech and $m b h$, two cytoplasmic [FeFe] hydrogenases hyd and hydll, and one cytoplasmic [NiFe] hydrogenase shi. The combined deletion of ech, $m b h$, shi and hydG resulted in a strain that did not produce hydrogen and showed no methyl viologen hydrogenase activity in cell extracts. Strains with deletions of all the hydrogenases except one showed normal hydrogen production. Methyl viologen hydrogenase activity was greatly reduced in all combined deletion strains except the strain with an intact hydG gene.

\section{Conclusion}

High hydrogen production and hydrogenase activities have been observed for T. ethanolicus. Five hydrogenases have been identified. Hydrogen production was eliminated by deleting genes required for all five hydrogenases. Each individual hydrogenase was verified to be capable of producing hydrogen during fermentation, indicating a high degree of redundancy and flexibility in the hydrogenase systems of $T$. ethanolicus. A large portion of hydrogenase activity is encoded by the [Fe-Fe] hydrogenases.

\section{Background}

Biofuel production from lignocellulosic biomass is a significant constituent of the global fuel supply in scenarios for a sustainable energy future [1], but improved biocatalysts are needed to reduce the costs of biomass conversion. Thermoanaerobacter ethanolicus is a gram-positive, anaerobic thermophilic bacterium that produces ethanol as the primary fermentation product from a wide range of polymeric and soluble carbohydrates [2] and is of interest for bioconversion processes [3]. It is also of interest as a co-culture companion for use with cellulolytic thermophilic microorganisms such as Clostridium thermocellum in one-step consolidated bioprocessing [4-6]. Due to the coupling of hydrogenase activity with fermentation product distribution, manipulation of hydrogenase activity has been identified as a method to direct metabolic flux to ethanol in Thermoanaerobacterium saccharolyticum [7]. Thus, understanding hydrogen production of T. ethanolicus, particularly the genes responsible, is valuable for further metabolic engineering of the species.

Hyrdrogenases are broadly classified according to the metal cofactors of their active sites as [Fe], [FeFe], and [NiFe] hydrogenases, but have deep evolutionary origins and fulfill a wide array of metabolic and energetic roles for bacteria and archea $[8,9]$. Depending on enzyme and cofactor properties as well as reactant concentrations, the hydrogenase reaction can potentially proceed in either direction. In the case of sugar fermenting anaerobes like $T$. 
ethanolicus, the reaction is often $\mathrm{H}_{2}$ generating and proton and electron consuming. Such bacteria use hydrogenases to eliminate excess reduced cofactors such as $\mathrm{NAD}(\mathrm{P}) \mathrm{H}$ or ferredoxin formed during sugar oxidation. Energy conservation is imperative, so hydrogenase reactions are tightly regulated, and diverse means have evolved for coupling the reaction energy to other cellular processes. For example, many membrane-associated [NiFe] hydrogenases conserve energy by coupling $\mathrm{H}_{2}$ production with generation of a proton or sodium gradient across the cell membrane. Specific examples are the Energy Conserving Hydrogenase (Ech) of T. tengcongensis and the Membrane Bound Hydrogenase (Mbh) of Pyrococcus furiosus [10,11]. The ech hydrogenase has a cluster of hyp genes in the same operon [7, 10]. The $m b h$ and $m b x$ hydrogenases have a cluster of antiporters [12-14]. Hydrogenases also occur in the cytoplasm, where energy is conserved by the coupling of $\mathrm{H}_{2}$ production and transhydrogenation in the bifurcating [FeFe] hydrogenases [15, 16].

Genetic manipulation via gene deletion has been applied to study hydrogenases in thermophilic bacteria. In $T$. saccharolyticum, [NiFe] hydrogenase ech-hyp and [FeFe] hydrogenase hyd were deleted individually or in combination, and the mutants were characterized with respect to hydrogen production and hydrogenase activity [7]. A [FeFe] hydrogenase with putative sensory function called $h f s$ was responsible for most of the hydrogen production under the conditions tested. Further studies of the four $h f s$ genes showed that deletion of $h f s A$ or $h f s B$ resulted in high ethanol yield [17]. In Clostridium thermocellum, [FeFe] hydrogenase activities were eliminated by deleting the hydrogenase maturase gene hydG and [NiFe] hydrogenase was eliminated by deletion of ech-hyp [18]. In $P$. furiosus, $\mathrm{H}_{2}$ production was eliminated by deletion of genes for the membrane bound hydrogenase Mbh and cytoplasmic hydrogenases SHI and SHII [19].

A markerless gene deletion and integration system has been developed for T. ethanolicus JW200 [20]. Three alcohol dehydrogenases have been characterized for their roles in ethanol production via gene deletions [21]. In this study, we identified hydrogenases in T. ethanolicus through BLAST searching, and deleted genes individually and in combination to gain insight into the activities and functions of the identified enzymes.

\section{Results And Discussion}

\section{Identification of membrane-bound [NiFe] and cytoplasmic [FeFe] hydrogenases}

To identify potential hydrogenases, a BLAST search of the $T$. ethanolicus genome was conducted using the hydrogenases reported for T. saccharolyticum [7]. The search identified four gene clusters with similarity to ech and hyd genes, as shown in Table 3. No matches were found in T. ethanolicus for the hfs genes of T. saccharolyticum. The genomic organization of the identified hydrogenase gene clusters in T. ethanolicus is shown in Figure 1. Based on the genetic grouping and similarity to known hydrogenases, the first two are likely to be membrane-bound [NiFe] hydrogenases while the last two are likely to be cytoplasmic [FeFe] hydrogenases. The first gene cluster similar to ech is composed of 12 genes with six genes for ech and six more matching the hyp [NiFe] maturation genes. The second gene cluster similar to T. saccharolyticum ech is composed of seven genes, similar to the $m b h$ genes of $P$. furiosus, as described below. The five hyd genes of T. saccharolyticum match five similar genes in T. ethanolicus, and appear to encode hydABCD, the four-subunit cytoplasmic bifurcating hydrogenase. The gene named hydll in $T$. saccharolyticum has a match in $T$. ethanolicus but is the only hydrogenase in its genomic neighborhood. In $T$. saccharolyticum, hydll is $2 \mathrm{Kbp}$ upstream of hyd. 
In addition to hydrogenase genes from T. saccharolyticum, hydrogenase genes from two other species were used as BLAST queries as well. The $C$. thermocellum hydG maturase gene was used to identify a similar gene (TheetDRAFT_1696) in the T. ethanolicus genome. A BLAST search using the 14-gene mbh operon from P. furiosus identified a 13-gene cluster in T. ethanolicus, of which seven genes are the second cluster of ech-like genes previously identified using $T$. saccharolyticum sequences. Immediately upstream of those seven ech-like genes are a cluster of six genes annotated as cation/H+ antiporters. A similar genetic organization occurs for the $m b h$ membrane-bound [NiFe] hydrogenase genes in $P$. furiosus [13]. Besides $m b h$, an $m b x$ hydrogenase and two foursubunit [NiFe] Soluble Hydrognases SHI and SHII have been reported in P. furiosus [19]. A BLAST search using SHI and SHII as queries identified a single cluster of four genes which are annotated as sulfite reductase. The gene configuration of this cluster is shown in Figure 1. The coding sequences for the first two subunits (A and B) overlap, and in some other species occur as a single gene. Subunit $C$ is an oxidoreductase FAD/NAD(P)-binding domain protein with electron transfer subunit and iron-sulfur cluster binding domain. Subunit D is a 4Fe-4S ferredoxin ironsulfur binding domain-containing protein. The gene cluster was named shi for Soluble Hydrogenase I. It likely encodes an NADPH-linked cystoplasmic hydrogenase based on its similarity to the genes in P. furiosus,

The SHI and SHII hydrogenases have been well characterized in P. furiosus, and due to in vitro sulfur reductase activity were previously thought to play a role in sulfur metabolism [22]. However, that is no longer the case due to observed down regulation of the corresponding genes when elemental sulfur is present [19]. Our search for hydrogenases in T. ethanolicus led us to $P$. furiosus when we noticed the smell of hydrogen sulfide from spent cultures, but we believe that the shigenes are in fact unrelated to sulfur metabolism.

\section{Deletion of all hydrogenase activities}

Strains were constructed with deletions for the genes responsible for hydrogen production in T. ethanolicus (Table 1). All strains carry a deletion of the $t d k$ gene encoding thymidine kinase, which allows counterselection against integrated gene cassettes and generation of markerless mutations [20]. Rather than deleting the hyd and hydll clusters individually, a single deletion was made for $h y d G$, which has been shown to effectively eliminate [FeFe] hydrogenase activity in $C$. thermocellum [18].

The strain with all four identified hydrogenase systems inactivated was named HO. Fermentation products were measured in batch bottle fermentations for $\mathrm{HO}$ and other intermediate strains and compared to the wildtype (WT) strain and the $t d k$ deletion strain (WT_tdk). As shown in Table 4, hydrogen production is eliminated in strain $\mathrm{H} 0$, and acetate levels are 10-fold lower than the controls. Lactate was the major product of strain $\mathrm{HO}$ with a mass yield about $84 \%$, while ethanol was much lower than the control, at $7.6 \mathrm{mM}$ vs. $18-34 \mathrm{mM}$. The shift from ethanol and acetate production to lactate production implies pyruvate is not being efficiently converted to acetyl-coA via pyruvate:ferredoxin oxidoreductase in strain $\mathrm{HO}$. Hydrogen production by ferredoxin-linked hydrogenases results in re-oxidation of reduced ferredoxin [23], which is required by pyruvate:ferredoxin oxidoreductase. There is no pyruvate formate lyase or pyruvate dehydrogenase in T. ethanolicus. Thus, removing hydrogen production may shift the flux of pyruvate from acetyl-coA to lactate.

\section{Analysis of strains with one intact hydrogenase}

Fermentation profiles of intermediate strains with three out of four hydrogenase systems deleted are also listed in Table 4. These strains retain only one hydrogenase while the other three are deleted. As shown in Table 4, strains $\mathrm{H} 1, \mathrm{H} 2, \mathrm{H} 3$, and $\mathrm{H} 4$ retain only ech, $m b h$, hyd, and shi, respectively. All these strains produce significant amount of hydrogen, suggesting that all four hydrogenases are potentially active in WT and that any of them can compensate 
for deletion of the others. Production of ethanol, lactate, acetate, and hydrogen is similar for $\mathrm{H} 1$, $\mathrm{H} 2$, and $\mathrm{H} 4$, while $\mathrm{H} 3$ produces about $20 \%$ less ethanol and more organic acid and hydrogen. The hydrogenases in $\mathrm{H} 1, \mathrm{H} 2$, and $\mathrm{H} 4$ are likely to be [NiFe] hydrogenases while those in $\mathrm{H} 3$ are [FeFe] hydrogenases. [FeFe] hydrogenases typically possess higher hydrogen evolution rates than [NiFe] hydrogenases and are often the targets of studies for biohydrogen production [24].

Relative to WT, the intermediate strains and WT_tdk showed lower lactate and higher ethanol levels. It is unknown why the fermentation products of WT_tdk differ somewhat from WT, but wide variation in the fermentation product profile was observed in the original species description of T. ethanolicus [2].

\section{Methyl viologen hydrogenase activity}

During efforts to create an ethanologenic strain of $T$. ethanolicus, the authors noticed high in vitro hydrogenase activity, up to 50 times greater than that of Thermoanaerobacterium saccharolyticum reported previously [7]. Methyl viologen (MV) hydrogenase activity was assayed with cleared lysate cell extracts for strains $\mathrm{H0}, \mathrm{H} 1, \mathrm{H} 2, \mathrm{H} 3$, H4, WT, and WT_tdk. MV acts as a universal electron acceptor-donor and can interact with hydrogenases that have either $\mathrm{NAD}(\mathrm{P}) \mathrm{H}$ or ferredoxin as a natural substrate [25]. Strain $\mathrm{HO}$, which does not produce hydrogen, exhibited a small background hydrogenase activity. Strain $\mathrm{H} 3$, producing the highest amount of hydrogen, shows the highest hydrogenase activity among the mutants $(\mathrm{H} 1, \mathrm{H} 2, \mathrm{H} 3, \mathrm{H} 4)$ with only one hydrogenase. However, with around $10 \%$ higher hydrogen production for $\mathrm{H} 3$ compared to the other three strains, its hydrogenase activity is 10 times higher. Although it is expected that the majority of enzymatic activity present in whole cells is also present in the cleared lysates, it is possible that enzymatic activity present in the membrane fraction $(\mathrm{H} 1$ and $\mathrm{H} 2)$ could be underrepresented [7]. For strains WT and WT_tdk, they both have all the hydrogenases and produce comparable amount of hydrogen. However, the WT strain shows a hydrogenase activity about five times that of the WT_tdk strain. The WT strain gives twice the hydrogenase activity of $\mathrm{H} 3$, while the WT_tdk strain has $40 \%$ hydrogenase activity of H3. Nevertheless, WT, WT_tdk, and H3 produce almost the same amount of hydrogen. High hydrogenase activity does not correlate to high hydrogen production in T. ethanolicus, which has also been reported for $T$. saccharolyticum [7]. The hydrogenases in T. ethanolicus, all capable of producing hydrogen, seem to be at standby mode to balance redox reactions for pyruvate metabolism to acetyl-CoA. When fermentation goes in the direction of ethanol production, a small amount of hydrogen is produced. When fermentation goes in the direction of organic acids, more hydrogen is produced. This might explain why variations in product ratios occur in the fermentation of wild-type T. ethanolicus [2, 20].

\section{Conclusion}

High hydrogen production and hydrogenase activities have been observed for $T$. ethanolicus. Five hydrogenases have been identified by sequence analysis including three [NiFe] hydrogenases and two [FeFe] hydrogenases. Hydrogen production was eliminated by deleting genes required for all five hydrogenases. With the two [FeFe] hydrogenases grouped as one and their activities removed by deleting the maturase gene hydG, each individual hydrogenase was verified to be capable of producing hydrogen during fermentation, indicating a high degree of redundancy and flexibility in the hydrogenase systems of $T$. ethanolicus. A large portion of hydrogenase activity is encoded by the [Fe-Fe] hydrogenases.

\section{Material And Methods}




\section{Strains and culturing conditions}

Thermoanaerobacter ethanolicus JW200 (ATCC 31550) was obtained from ATCC. Mutant strains constructed in this study are listed in Table 1 . The strains were cultured in CTFUD medium [26] with or without $0.8 \%$ (w/v) agar with an initial $\mathrm{pH}$ of 7 at $65^{\circ} \mathrm{C}$.

\section{Construction of mutant strains}

DNA fragments were amplified by PCR using the primers listed in Table 2, then purified by gel electrophoresis. Construction of vectors, transformation, and mutant selection were performed according to a markerless gene deletion and integration system reported previously (Shao et al., 2016). Gene deletion PCR products were amplified directly from the Gibson Assembly mixture using primers p29 and p30. The PCR products were then column purified and transformed into target strains.

PCR amplification and colony PCR were both performed with Phusion High-Fidelity PCR Master Mix with HF Buffer (New England Biolabs). Plasmid was extracted using QIAprep Spin Miniprep Kit (Qiagen). Backbone plasmid digestion was performed with Pvull-HF in CutSmart Buffer (New England Biolabs) at $50^{\circ} \mathrm{C}$ for $15 \mathrm{~min}$. Gel purification was performed on $1 \%$ agarose gel with $0.01 \%(\mathrm{v} / \mathrm{v})$ SYBR Safe DNA Gel Stain florescent indicator (Thermo Fisher Scientific) and recovered using Zymoclean Gel DNA Recovery Kit (Zymo Research). Plasmids were constructed with Gibson Assembly Master Mix (New England Biolabs) at $50^{\circ} \mathrm{C}$ for $1 \mathrm{~h}$.

\section{Measurement of fermentation products}

Wild-type and the mutant strains were cultured in CTFUD medium with cellobiose at an initial concentration of 5 $\mathrm{g} / \mathrm{L}$ in serum bottles sealed with butyl rubber stoppers. The reaction volume was $10 \mathrm{~mL}$ with $27 \mathrm{~mL}$ headspace filled with ultra-pure nitrogen. Inoculum prepared in the same medium was added at $1 \%(\mathrm{v} / \mathrm{v})$. The serum bottles were incubated at $65^{\circ} \mathrm{C}$ for two days in a shaking incubator (Innova 4080, New Brunswick Scientific, Edison, NJ) with a rotation speed of $200 \mathrm{rpm}$. Samples were taken for measurement of product concentrations. Liquid-phase fermentation products were measured using HPLC using an Aminex HPX-87H column (Bio-Rad, Hercules, CA) at $60^{\circ} \mathrm{C}$, with RI (refractive index) detection and a 5-mM sulfuric acid solution eluent at a flow rate of $0.6 \mathrm{ml} / \mathrm{min}$. Hydrogen was measured using gas chromatography using an SRI 310C gas chromatograph with a HayeSep D packed column using a thermal conductivity detector and nitrogen carrier gas at a flow rate of $8.2 \mathrm{ml} / \mathrm{min}$.

\section{Hydrogenase activity assays}

Wild-type and the mutant strains were cultured under the same conditions as for measurement of fermentation products, but cells were harvested in the exponential phase of growth. The procedures for preparation of cleared lysate extracts and methyl viologen-based hydrogenase activity assays were as reported previously (Shaw et al., 2009). One unit of enzymatic activity equals to one $\mu \mathrm{mol}$ of product formed per minute per mg of crude cell extract protein.

\section{Declarations}

\section{Ethics approval and consent to participate}

Not applicable.

\section{Consent for publication}


Not applicable.

\section{Availability of data and materials}

All data generated or analyzed during this study are included in this published article.

\section{Competing interests}

$\mathrm{CDH}$ is supported by Enchi Corporation, and LRL is supported by and has a financial interest in Enchi, which is a for-profit company that seeks to commercialize C-CBP technology.

\section{Funding}

The authors are grateful for the funding support from the Hubei University and the Center for Bioenergy Innovation, $\mathrm{CBI}$, and the Bioenergy Science Center (BESC), U.S. Department of Energy (DOE) Research Centers supported by the Office of Biological and Environmental Research in the DOE Office of Science.

\section{Author's contributions}

The authors discussed and designed the experiments together. XS, YZ, GZ performed the gene deletion experiments. LT measured the hydrogenase activities. All authors have revised the paper critically for intellectual content, and have read and approved the final manuscript.

\section{Acknowledgements}

Not applicable.

\section{References}

1. IEA. World Energy Outlook 2020. Paris: IEA; 2020. https://www.iea.org/reports/world-energy-outlook-2020.

2. Wiegel J, Ljungdahl L. Thermoanaerobacter ethanolicus gen. nov., spec. nov., a new, extreme thermophilic, anaerobic bacterium. Arch Microbiol. 1981;128:343-8.

3. Hild HM, Stuckey DC, Leak DJ. 2003. Effect of nutrient limitation on product formation during continuous fermentation of xylose with Thermoanaerobacter ethanolicus JW200 Fe(7). Appl Microbiol Biotechnol. 2003(60), 679-686.

4. Lynd LR, Weimer PJ, van Zyl WH, Pretorius IS. Microbial cellulose utilization: fundamentals and biotechnology. Microbiol Mol Biol Rev. 2002;66:506-77.

5. Argyros DA, Tripathi SA, Barrett TF, Rogers SR, Feinberg LF, Olson DG, Foden JM, Miller BB, Lynd LR, Hogsett DA, Caiazza NC. High ethanol titers from cellulose by using metabolically engineered thermophilic, anaerobic microbes. Appl Environ Microbiol. 2011;77:8288-94.

6. Beri D, Herring CD, Blahova S, Poudel S, Giannone RJ, Hettich RL, Lynd LR. Coculture with hemicellulosefermenting microbes reverses inhibition of corn fiber solubilization by Clostridium thermocellum at elevated solids loadings. Biotechnol Biofuels. 2021;14(1):24. doi:10.1186/s13068-020-01867-w.

7. Shaw AG, Hogsett DA, Lynd LR. Identification of the [FeFe]-Hydrogenase Responsible for Hydrogen Generation in Thermoanaerobacterium saccharolyticum and Demonstration of Increased Ethanol Yield via Hydrogenase Knockout. J Bacteriol. 2009;191(20):6457-64. 
8. Mulder DW, Shepard EM, Meuser JE, Joshi N, King PW, Posewitz MC, Broderick JB, Peters JW. Insights into [FeFe]-hydrogenase structure, mechanism, and maturation. Structure. 2011;19:1038-52.

9. Greening C, Biswas A, Carere CR, Jackson CJ, Taylor MC, Stott MB, Cook GM, Morales SE. Genomic and metagenomic surveys of hydrogenase distribution indicate $\mathrm{H} 2$ is a widely utilised energy source for microbial growth and survival. ISME J. 2016 Mar;10(3):761-77. doi:10.1038/ismej.2015.153.

10. Soboh B, Linder D, Hedderich R. A multisubunit membranebound [NiFe] hydrogenase and an NADH-dependent Fe-only hydrogenase in the fermenting bacterium Thermoanaerobacter tengcongensis. Microbiology. 2004;150:2451-63.

11. Sapra R, Bagramyan K, Adams MW. A simple energy-conserving system: proton reduction coupled to proton translocation. Proc Natl Acad Sci U S A. 2003;100(13):7545-50. doi:10.1073/pnas.1331436100.

12. Kanai T, Simons J-R, Tsukamoto R, Nakajima A, Omori Y, Matsuoka R, Beppu H, Imanaka T, Atomi H. Overproduction of the membrane-bound [NiFe]-hydrogenase in Thermococcus kodakarensis and its effect on hydrogen production. Front Microbiol. 2015;6:847.

13. Schut GJ, Bridger SL, Adams MWW. Insights into the metabolism of elemental sulfur by the hyperthermophilic archaeon Pyrococcus furiosus: Characterization of a coenzyme A-dependent NAD(P)H sulfur oxidoreductase. J Bacteriol. 2007;189(12):4431-41.

14. Silva PJ, van den Ban EC, Wassink H, Haaker H, de Castro B, Robb FT, Hagen WR. Enzymes of hydrogen metabolism in Pyrococcus furiosus. Eur J Biochem. 2000;267:6541-51.

15. Schut GJ, Adams MW. The iron-hydrogenase of Thermotoga maritima utilizes ferredoxin and NADH synergistically: a new perspective on anaerobic hydrogen production. J Bacteriol. 2009;191(13):4451-7.

16. Schuchmann K, Chowdhury NP, Müller V. Complex Multimeric [FeFe] Hydrogenases: Biochemistry, Physiology and New Opportunities for the Hydrogen Economy. Front Microbiol. 2018;9:2911. doi:10.3389/fmicb.2018.02911.

17. Eminoğlu A, Murphy SJ-L, Maloney M, Lanahan A, Giannone RJ, Hettich RL, Tripathi SA, Beldüz AO, Lynd LR. Deletion of the $h f s B$ gene increases ethanol production in Thermoanaerobacterium saccharolyticum and several other thermophilic anaerobic bacteria. Biotechnol Biofuels. 2017;10:282. doi:10.1186/s13068-0170968-9.

18. Biswas R, Zheng T, Olson DG, Lynd LR, Guss AM. 2015. Elimination of hydrogenase active site assembly blocks $\mathrm{H} 2$ production and increases ethanol yield in Clostridium thermocellum. Biotechnol Biofuels 8(20), DOI 10.1186/s13068-015-0204-4.

19. Schut GJ, Nixon WJ, Lipscomb GL, Scott RA, Adams MWW. Mutational analyses of the enzymes involved in the metabolism of hydrogen by the hyperthermophilic archaeon Pyrococcus furiosus. Front Microbiol. 2012;3:163. doi:10.3389/fmicb.2012.00163.

20. Shao X, Zhou J, Olson DG, Lynd LR. A markerless gene deletion and integration system for Thermoanaerobacter ethanolicus. Biotechnol Biofuels. 2016;9:100.

21. Zhou J, Shao X, Olson DG, Murphy SJ-L, Liang T, Lynd LR. Determining the roles of the three alcohol dehydrogenases (AdhA, AdhB and AdhE) in Thermoanaerobacter ethanolicus during ethanol formation. $J$ Ind Microbiol Biotechnol. 2017;44(4-5):745-57.

22. Ma K, Weiss R, Adams MWW. Characterization of Hydrogenase II from the Hyperthermophilic Archaeon Pyrococcus furiosus and Assessment of Its Role in Sulfur Reduction. J Bacteriol. 2000;182(7):1864-71. 
23. Carere CR, Rydzak T, Verbeke TJ, Cicek N, Levin DB, Sparling R. Linking genome content to biofuel production yields: a meta-analysis of major catabolic pathways among select $\mathrm{H} 2$ and ethanol-producing bacteria. BMC Microbiol. 2012;12:295.

24. Adams MWW. The structure and mechanism of iron-hydrogenases. Biochim Biophys Acta. 1990;1020:115-45.

25. Verhagen M, Adams MW. Fe-only hydrogenase from Thermotoga maritima. Methods Enzymol. 2001;331:21626.

26. Olson DG, Lynd LR. Transformation of Clostridium thermocellum by electroporation. In: Gilbert HJ, editor. Methods in enzymology. Vol. 510. Amsterdam: Elsevier Inc; 2012. pp. 317-30.

\section{Tables}

Table 1

List of strains and their genotypes

\begin{tabular}{|ll|}
\hline Strains & Description/Genotype \\
\hline WT & Wild type strain, ATCC 31550 \\
\hline WT_tdk & $\Delta t d k$ \\
\hline H0 & $\Delta t d k \Delta e c h-h y p \Delta m b h \Delta h y d G \Delta s h i$ \\
\hline H1 & $\Delta t d k \Delta m b h \Delta h y d G \Delta s h i$ \\
\hline H2 & $\Delta t d k \Delta e c h-h y p \Delta h y d G \Delta s h i$ \\
\hline H3 & $\Delta t d k \Delta e c h-h y p \Delta m b h \Delta s h i$ \\
\hline H4 & $\Delta t d k \Delta e c h-h y p \Delta m b h \Delta h y d G$ \\
\hline Note: the gene cluster ech2 is a major fraction of $m b h$ \\
\hline
\end{tabular}


Table 2

List of primers used

\begin{tabular}{|c|c|c|}
\hline Name & Sequence & Function \\
\hline p1 & TTAACCTATAAAAATAGGCGTATCACGAGATGCATCAGCGCCCTGAAGAAGTAACTGACA & $\begin{array}{l}t d k \\
\text { upstream } \\
\text { fwd }\end{array}$ \\
\hline p2 & CCACCTATATCGGTTTTCTTCATCTCTACACCTCTTTTAGTCTTCACCACTCTAACCCCC & $\begin{array}{l}t d k \\
\text { upstream } \\
\text { rev }\end{array}$ \\
\hline p3 & AAAAGAGGTGTAGAGATGAAGAAAACC & $\begin{array}{l}t d k \\
\text { downstream } \\
\text { fwd }\end{array}$ \\
\hline p4 & CTCCCCGCGCGTTGGCCGATTCATTAATGATGCATCAGGCAGTTCCGCTTCAAGTTTAGG & $\begin{array}{l}\text { tdk } \\
\text { downstream } \\
\text { rev }\end{array}$ \\
\hline p5 & CATTAACCTATAAAAATAGGCGTATCACGAGATGCATCAGGCAGACAGACAAAGAAGACA & $\begin{array}{l}\text { ech-hyp } \\
\text { upstream } \\
\text { fwd }\end{array}$ \\
\hline p6 & CTAGAGCTTCCTCCGCATATTTCCTGTCAACAACCGCAATTACACCCAAAGATACAGCAA & $\begin{array}{l}\text { ech-hyp } \\
\text { upstream } \\
\text { rev }\end{array}$ \\
\hline p7 & TAATCTTTTCTGAAGTACATCCGCAACTGTCCATACTCCAGCTTCCAGAGTTGGCTTCTT & $\begin{array}{l}\text { ech-hyp } \\
\text { internal fwd }\end{array}$ \\
\hline p8 & СTCTCCCCGCGCGTTGGCCGATTCATTAATGATGCATCAGACATCATACCCATCCTCTTC & $\begin{array}{l}\text { ech-hyp } \\
\text { internal rev }\end{array}$ \\
\hline p9 & AATTGCGGTTGTTGACAG & $\begin{array}{l}\text { ech-hyp } \\
\text { downstream } \\
\text { fwd }\end{array}$ \\
\hline p10 & TACCTATCACCTCAAATGGTTCGCTGGGTTTTACGCAGTCTTTCTTCTCСTCTCСTCTTT & $\begin{array}{l}\text { ech-hyp } \\
\text { downstream } \\
\text { rev }\end{array}$ \\
\hline $\mathrm{p} 11$ & ACATTAACCTATAAAAATAGGCGTATCACGAGATGCATCAGGGGACTCTATTTCAAGGGG & $\begin{array}{l}m b h \\
\text { upstream } \\
\text { fwd }\end{array}$ \\
\hline $\mathrm{p} 12$ & TATATCATCTCCCAAAGATTCATCCGGCAGAAGCTTAAATTAGTCACACCTCCATTTTCA & $\begin{array}{l}m b h \\
\text { upstream } \\
\text { rev }\end{array}$ \\
\hline $\mathrm{p} 13$ & СTAATCTTTTCTGAAGTACATCCGCAACTGTCCATACTCCAGACCAGGAGGCGTTAGAAA & $\begin{array}{l}m b h \\
\text { internal fwd }\end{array}$ \\
\hline p14 & СTCTCCCCGCGCGTTGGCCGATTCATTAATGATGCATCAGACATCTACGCAAAATCCACA & $\begin{array}{l}m b h \\
\text { internal rev }\end{array}$ \\
\hline p15 & AATTTAAGCTTCTGCCGGA & $\begin{array}{l}\text { mbh } \\
\text { downstream } \\
\text { fwd }\end{array}$ \\
\hline p16 & TTACCTATCACCTCAAATGGTTCGCTGGGTTTTACGCAGTTCTCATCTGCCTCAACATCT & $\begin{array}{l}m b h \\
\text { downstream } \\
\text { rev }\end{array}$ \\
\hline
\end{tabular}




\begin{tabular}{|c|c|c|}
\hline Name & Sequence & Function \\
\hline p17 & ACATTAACCTATAAAAATAGGCGTATCACGAGATGCATCAGAATGTGTTGGATTTAGCGG & $\begin{array}{l}\text { hydG } \\
\text { upstream } \\
\text { fwd }\end{array}$ \\
\hline p18 & CCATTTTCTATTCTTTTTAGTCTTCTCTTTGTCTCTTCCCTTTTTATCTCCTCCCTCGCC & $\begin{array}{l}\text { hydG } \\
\text { upstream } \\
\text { rev }\end{array}$ \\
\hline p19 & TCTTTTCTGAAGTACATCCGCAACTGTCCATACTCCAGGTTGAGATTTTGGAAGAGATGG & $\begin{array}{l}\text { hydG } \\
\text { internal fwd }\end{array}$ \\
\hline p20 & CTCTCCCCGCGCGTTGGCCGATTCATTAATGATGCATCAGCTTTGTTTTTTCATCCCCGT & $\begin{array}{l}\text { hydG } \\
\text { internal rev }\end{array}$ \\
\hline p21 & AAGGGAAGAGACAAAGAGAAG & $\begin{array}{l}\text { hydG } \\
\text { downstream } \\
\text { fwd }\end{array}$ \\
\hline p22 & АTCTTACCTATCACCTCAAATGGTTCGCTGGGTTTTACGCAGAGAAGTGGTAACGCCAAA & $\begin{array}{l}\text { hydG } \\
\text { downstream } \\
\text { rev }\end{array}$ \\
\hline p23 & ACATTAACCTATAAAAATAGGCGTATCACGAGATGCATCAGCTTTTTTTCTCTGCCCACC & $\begin{array}{l}\text { shi } \\
\text { upstream } \\
\text { fwd }\end{array}$ \\
\hline p24 & GTATTCGGTTTCTGTCCATAATACCCTTTCAGCCACCATAACTCATCTTCTTCCTCCTCA & $\begin{array}{l}\text { shi } \\
\text { upstream } \\
\text { rev }\end{array}$ \\
\hline p25 & CTAATCTTTTCTGAAGTACATCCGCAACTGTCCATACTCCAGATGCACTTTGCCGCTTTA & $\begin{array}{l}\text { shi internal } \\
\text { fwd }\end{array}$ \\
\hline p26 & СTCTCCCCGCGCGTTGGCCGATTCATTAATGATGCATCAGGTTTGTTTTCCTGTTCTGCC & $\begin{array}{l}\text { shi internal } \\
\text { rev }\end{array}$ \\
\hline p27 & TATGGTGGCTGAAAGGGT & $\begin{array}{l}\text { shi } \\
\text { downstream } \\
\text { fwd }\end{array}$ \\
\hline p28 & ATCTTACCTATCACCTCAAATGGTTCGCTGGGTTTTACGCAGCTCAGCAGATCATTGGGT & $\begin{array}{l}\text { shi } \\
\text { downstream } \\
\text { rev }\end{array}$ \\
\hline p29 & AATTCTCTTACTGTCATGCC & $\begin{array}{l}\text { Deletion } \\
\text { PCR product } \\
\text { fwd }\end{array}$ \\
\hline p30 & GAGAAAGGCGGACAGGTA & $\begin{array}{l}\text { Deletion } \\
\text { PCR product } \\
\text { rev }\end{array}$ \\
\hline
\end{tabular}


Table 3

Identification of potential hydrogenases in T. ethanolicus

\begin{tabular}{|c|c|c|c|c|}
\hline Organism & Query & Query Description & Match in T. ethanolicus & Name $^{*}$ \\
\hline \multirow{4}{*}{$\begin{array}{l}\text { T. } \\
\text { saccharolyticum } \\
\text { JW/SL-YS485 }\end{array}$} & $\begin{array}{l}\text { Tsac_0675 to } \\
\text { Tsac_0686 }\end{array}$ & $\begin{array}{l}\text { ech membrane-bound [NiFe] } \\
\text { hydrogenase \& hyp maturation } \\
\text { genes }\end{array}$ & $\begin{array}{l}\text { TheetDRAFT_0034 to } \\
\text { TheetDRAFT_0045 }\end{array}$ & $\begin{array}{l}\text { ech- } \\
\text { hyp }\end{array}$ \\
\hline & $\begin{array}{l}\text { Tsac_0675 to } \\
\text { Tsac_0680 }\end{array}$ & $\begin{array}{l}\text { ech membrane-bound [NiFe] } \\
\text { hydrogenase }\end{array}$ & $\begin{array}{l}\text { TheetDRAFT_1117 to } \\
\text { TheetDRAFT_1123 }\end{array}$ & $m b h$ \\
\hline & $\begin{array}{l}\text { Tsac_2126 to } \\
\text { Tsac_2130 }\end{array}$ & hyd [FeFe] hydrogenase & $\begin{array}{l}\text { TheetDRAFT_2222 to } \\
\text { TheetDRAFT_2226 }\end{array}$ & hyd \\
\hline & Tsac_2133 & hydII [FeFe] hydrogenase & TheetDRAFT_2777 & hydll \\
\hline $\begin{array}{l}\text { C. thermocellum } \\
\text { DSM } 1313\end{array}$ & Clo1313_1571 & $\begin{array}{l}\text { hydG [FeFe] hydrogenase } \\
\text { maturation gene }\end{array}$ & TheetDRAFT_1696 & hydG \\
\hline \multirow{3}{*}{$\begin{array}{l}\text { P. furiosus } \\
\text { DSM } 3638\end{array}$} & $\begin{array}{l}\text { PF1423 to } \\
\text { PF1436 }\end{array}$ & $\begin{array}{l}\text { mbh membrane-bound [NiFe] } \\
\text { hydrogenase }\end{array}$ & $\begin{array}{l}\text { TheetDRAFT_1117 to } \\
\text { TheetDRAFT_1129 }\end{array}$ & $m b h$ \\
\hline & $\begin{array}{l}\text { PF0891 to } \\
\text { PF0894 }\end{array}$ & Soluble hydrogenase SHI & $\begin{array}{l}\text { TheetDRAFT_1019 to } \\
\text { TheetDRAFT_1022 }\end{array}$ & shi \\
\hline & $\begin{array}{l}\text { PF1329 to } \\
\text { PF1332 }\end{array}$ & Soluble hydrogenase SHII & $\begin{array}{l}\text { TheetDRAFT_1019 to } \\
\text { TheetDRAFT_1022 }\end{array}$ & shi \\
\hline
\end{tabular}


Table 4

Fermentation profiles of mutants with individual hydrogenase

\begin{tabular}{|c|c|c|c|c|c|}
\hline Strain & Genotype & Ethanol $\mathrm{mM}$ & $\begin{array}{l}\text { Lactate } \\
\mathrm{mM}\end{array}$ & Acetate $\mathrm{mM}$ & Hydrogen $\mathrm{mM}$ \\
\hline \multirow[t]{2}{*}{$\mathrm{HO}$} & $\Delta t d k \Delta e c h-h y p \Delta m b h \Delta h y d G \Delta s h i$ & 7.6 & 49.0 & 0.8 & 0 \\
\hline & & \pm 0.09 & \pm 0.14 & \pm 0.01 & \pm 0 \\
\hline \multirow[t]{2}{*}{$\mathrm{H} 1$ (ech-hyp) } & $\Delta t d k \Delta m b h \Delta h y d G \Delta s h i$ & 36.7 & 6.8 & 11.3 & 29.5 \\
\hline & & \pm 0.02 & \pm 0.15 & \pm 0.07 & \pm 0.32 \\
\hline \multirow[t]{2}{*}{$\mathrm{H} 2(m b h)$} & $\Delta t d k \Delta e c h-h y p \Delta h y d G \Delta s h i$ & 35.9 & 6.9 & 12.2 & 31.0 \\
\hline & & \pm 0.15 & \pm 0.43 & \pm 0.13 & \pm 0.41 \\
\hline \multirow[t]{2}{*}{$\mathrm{H} 3(h y d G)$} & $\Delta t d k \Delta e c h-h y p \Delta m b h \Delta s h i$ & 27.8 & 9.6 & 14.2 & 34.9 \\
\hline & & \pm 0.19 & \pm 0.03 & \pm 0.15 & \pm 0.34 \\
\hline \multirow[t]{2}{*}{ H4(shi) } & $\Delta t d k \Delta e c h-h y p \Delta m b h \Delta h y d G$ & 35.9 & 7.0 & 12.1 & 30.7 \\
\hline & & \pm 0.05 & \pm 0.18 & \pm 0.14 & \pm 0.21 \\
\hline \multirow[t]{2}{*}{ WT } & & 18.2 & 26.1 & 12.3 & 27.8 \\
\hline & & \pm 0.21 & \pm 0.58 & \pm 0.09 & \pm 0.01 \\
\hline \multirow[t]{2}{*}{ WT_tdk } & $\Delta t d k$ & 34.3 & 6.5 & 11.5 & 27.6 \\
\hline & & \pm 0.15 & \pm 0.01 & \pm 0.16 & \pm 0.25 \\
\hline
\end{tabular}

Table 5

Methyl viologen hydrogenase activity in whole cell extracts

\begin{tabular}{|lll|}
\hline Strain & Genotype & $\begin{array}{l}\text { MV hydrogenase } \\
\text { specific activity, U/mg }\end{array}$ \\
\hline H0 & $\Delta t d k \Delta e c h-h y p \Delta m b h \Delta h y d G \Delta s h i$ & $1.5 \pm 0.19$ \\
\hline H1(ech-hyp) & $\Delta t d k \Delta m b h \Delta h y d G \Delta s h i$ & $2.5 \pm 0.33$ \\
\hline H2(mbh) & $\Delta t d k \Delta e c h-h y p \Delta h y d G \Delta s h i$ & $1.2 \pm 0.13$ \\
\hline H3(hydG) & $\Delta t d k \Delta e c h-h y p \Delta m b h \Delta s h i$ & $49.3 \pm 4.79$ \\
\hline H4(shi) & $\Delta t d k \Delta e c h-h y p \Delta m b h \Delta h y d G$ & $5.2 \pm 1.08$ \\
\hline WT & & $95.1 \pm 9.42$ \\
\hline WT_tdk & $\Delta t d k$ & $19.6 \pm 2.06$ \\
\hline
\end{tabular}

\section{Figures}



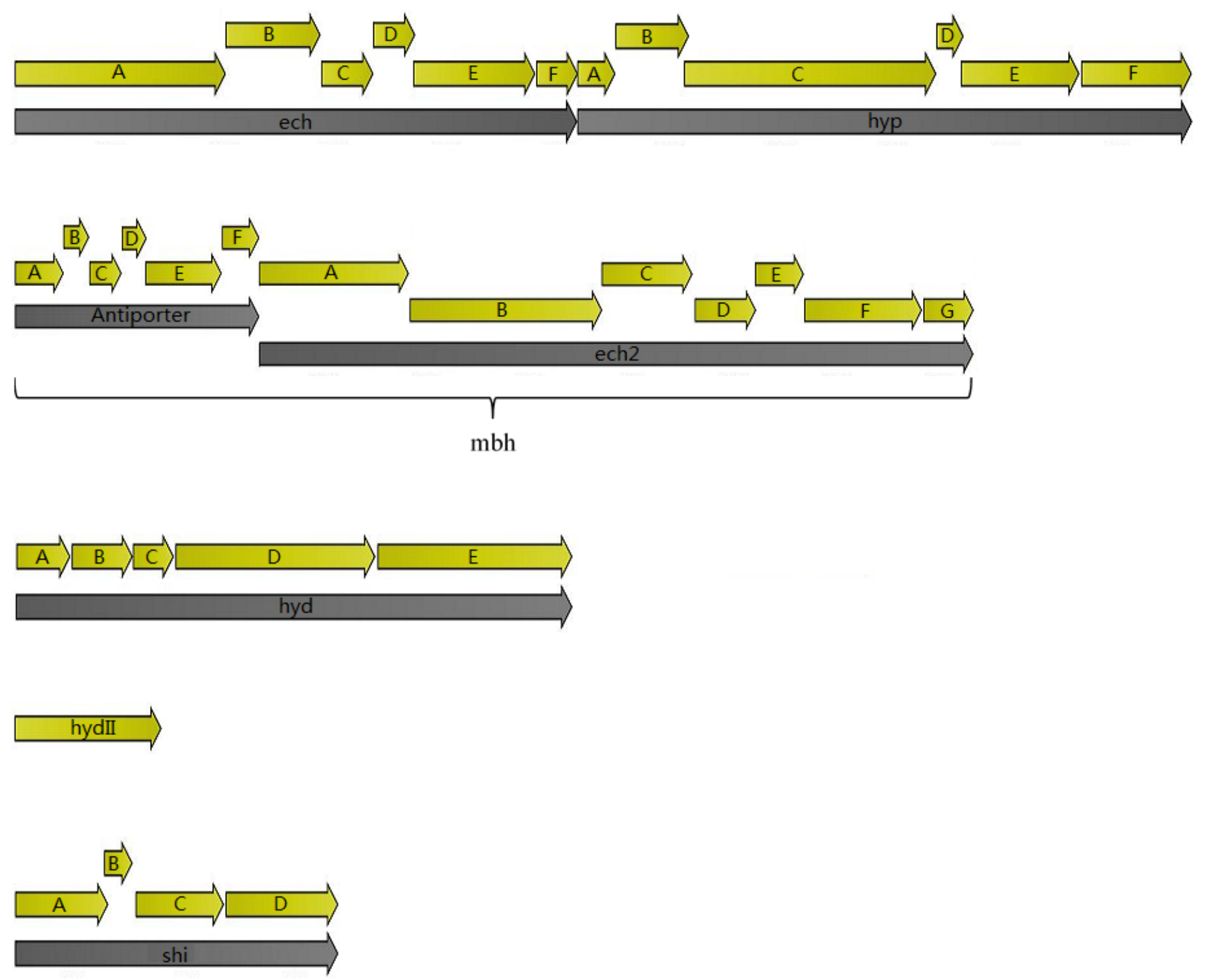

\section{Figure 1}

Genomic organization of hydrogenase gene clusters in T. ethanolicus 